\title{
Accommodation coefficient of HOBr on deliquescent sodium bromide aerosol particles
}

\author{
M. Wachsmuth ${ }^{1,2}$, H. W. Gäggeler ${ }^{1,2}$, R. von Glasow ${ }^{3, *}$, and M. Ammann ${ }^{1}$ \\ ${ }^{1}$ Paul Scherrer Institut, Laboratory for Radio- and Environmental Chemistry, Villigen, Switzerland \\ ${ }^{2}$ Also at Department of Chemistry and Biochemistry, University of Bern, Bern, Switzerland \\ ${ }^{3}$ Max-Planck-Institut für Chemie, Abt. Chemie der Atmosphäre, Mainz, Germany \\ *Present address: Center for Atmospheric Sciences, Scripps Institution of Oceanography, University of California, San Diego, \\ USA
}

Received: 12 October 2001 - Published in Atmos. Chem. Phys. Discuss.: 11 January 2002

Revised: 10 April 2002 - Accepted: 30 April 2002 - Published: 6 June 2002

\begin{abstract}
Uptake of $\mathrm{HOBr}$ on sea salt aerosol, sea salt brine or ice is believed to be a key process providing a source of photolabile bromine $\left(\mathrm{Br}_{2}\right)$ and sustaining ozone depletion cycles in the Arctic troposphere. In the present study, uptake of $\mathrm{HOBr}$ on sodium bromide $(\mathrm{NaBr})$ aerosol particles was investigated at an extremely low $\mathrm{HOBr}$ concentration of $300 \mathrm{~cm}^{-3}$ using the short-lived radioactive isotopes ${ }^{83-86} \mathrm{Br}$. Under these conditions, at maximum one $\mathrm{HOBr}$ molecule was taken up per particle. The rate of uptake was clearly limited by the mass accommodation coefficient, which was calculated to be $0.6 \pm 0.2$. This value is a factor of 10 larger than estimates used in earlier models. The atmospheric implications are discussed using the box model "MOCCA", showing that the increase of the accommodation coefficient of $\mathrm{HOBr}$ by a factor of 10 only slightly affects net ozone loss, but significantly increases chlorine release.
\end{abstract}

\section{Introduction}

Ozone plays an important role in the chemistry and the radiation budget of the troposphere. In the polar troposphere, episodes with very low ozone levels have been observed in the past twenty years in the Arctic (Galbally and Roy, 1980; Oltmans, 1981; Bottenheim et al., 1986; Oltmans and Komhyr, 1986) and the Antarctic (Wessel et al., 1998). These episodes occur frequently between polar sunrise and early summer and cover extended areas over the Arctic troposphere (Mickle, 1989). From the correlation between the sudden ozone loss events and the bromine content of the air mass (Barrie et al., 1988; Barrie et al., 1989) it was postulated that ozone is being depleted by reaction with the bromine radical, $\mathrm{Br}$ (Barrie et al., 1988; Bottenheim et al.,

Correspondence to: M. Ammann (markus.ammann@psi.ch)
1990; Finlayson-Pitts et al., 1990; Langendörfer et al., 1999). The presence of $\mathrm{BrO}$, the primary product of $\mathrm{O}_{3}$ with $\mathrm{Br}$, in the atmospheric boundary layer has been verified in situ during tropospheric ozone depletion events (Hausmann and Platt, 1994; Tuckermann et al., 1997; Stutz et al., 1999). Many suggestions have been made how sea salt bromide either in the sea salt aerosol or as brine on the sea ice surface could provide a source of photolabile $\mathrm{Br}_{2}$ as a source of $\mathrm{Br}$ radicals to sustain ozone destruction (Finlayson-Pitts et al., 1990; Fan and Jacob, 1992; McConnell et al., 1992; Le Bras and Platt, 1995; Mozurkewich, 1995; Tang and McConnell, 1996; Wessel et al., 1998; Langendörfer et al., 1999). A very efficient way to release $\mathrm{Br}_{2}$ into the gas-phase especially in the clean marine boundary layer is through autocatalytic cycles (Vogt et al., 1996) involving the reaction of $\mathrm{HOBr}$ with Bromide $\left(\mathrm{Br}^{-}\right)$(Fan and Jacob, 1992) in the sea salt solution,

$\mathrm{HOBr}+\mathrm{Br}^{-}+\mathrm{H}^{+} \leftrightarrow \mathrm{Br}_{2}+\mathrm{H}_{2} \mathrm{O}$

and its analogue with chloride. The bulk liquid phase chemistry of reaction (1) has been explored by Eigen and Kustin (1962), and with respect to its significance to the marine boundary layer, Fickert et al. (1999) investigated the $\mathrm{Br}_{2}$ and $\mathrm{BrCl}$ yield in the gas-phase for mixed bromide and chloride solutions as a function of $\mathrm{pH}$. This chemistry is not restricted to the Arctic boundary layer. In mid-latitudes at the Dead Sea, events with very high $\mathrm{BrO}$ concentrations were observed (Hebestreit et al., 1999), which were caused by bromine release from saltpans. In the sub-tropical North-western Pacific at Ogasawara Hahajima Island (Nagao et al., 1999) as well as in the mid-latitute Southwest pacific at Cape Grim (Galbally et al., 2000) a distinct sunrise ozone destruction (SOD) was observed. It was speculated that this is due to halogen (esp. bromine) reactions. Based on model calculations, Von Glasow et al. (2001) explained the diurnal variation of $\mathrm{BrO}$ 
with a peak early in the morning, which could be the cause of the SOD.

A quantitative understanding of ozone chemistry in the marine boundary layer and its reliable modelling requires a more detailed knowledge of the processes governing $\mathrm{HOBr}$ uptake from the gas-phase and its reaction in the liquid phase. The kinetics of a heterogeneous process is commonly described in terms of the uptake coefficient, $\gamma_{\text {upt }}$, defined as the probability that a molecule undergoing a gas-kinetic collision with the particle surface is actually undergoing processing on or beyond this surface (Hanson et al., 1994). The flux of reactive molecules from the surrounding gas to the particle surface depends on the particle size and the value of $\gamma_{\text {upt }}$. Macroscopically, this is accounted for by expressing the first order loss rate coefficient $k_{\mathrm{g}}^{1}$ of $\mathrm{HOBr}_{(\mathrm{g})}$ by

$k_{\mathrm{g}}^{\mathrm{I}}=\gamma_{\mathrm{net}} \cdot N_{\mathrm{p}} \pi d_{\mathrm{p}}^{2} \cdot \frac{v}{4}$,

where $\gamma_{\text {net }}$ denotes the net uptake coefficient, $N_{\mathrm{p}}$ the number density of particles $\left(\# / \mathrm{cm}^{3}\right), d_{\mathrm{p}}$ the particle diameter $(\mathrm{cm})$, and $v$ the mean thermal velocity $(\mathrm{cm} / \mathrm{s})$. Within this framework, $\gamma_{\text {net }}$ can be expressed as

$$
\frac{1}{\gamma_{\mathrm{net}}}=\frac{1}{\Gamma_{\mathrm{diff}}}+\frac{1}{\gamma_{\mathrm{upt}}}
$$

This notation indicates that the effect of diffusion to the particle surface is to add an additional resistance to uptake, and can also be understood as a correction to the purely gaskinetic flux to the surface area. The smaller $\gamma_{\text {upt }}$ and $d_{\mathrm{p}}$, the smaller is the contribution of $\Gamma_{\text {diff }}$ to $k_{\mathrm{g}}^{1}$. For the particle size range that is most relevant to atmospheric chemistry, Fuchs and Sutugin (1970) have derived an approximation:

$$
\frac{1}{\Gamma_{\text {diff }}}=\frac{0.75+0.28 K n}{K n(1+K n)}
$$

with the Knudsen number defined as

$$
K n=\frac{6 D}{v d_{\mathrm{p}}} \text {. }
$$

Along the same line as to include diffusion resistance, $\gamma_{\text {upt }}$ is represented as a superposition of accommodation and loss within the bulk liquid due to reaction:

$$
\frac{1}{\gamma_{\mathrm{upt}}}=\frac{1}{\alpha}+\frac{1}{\Gamma_{\mathrm{rxn}}}=\frac{1}{\alpha}+\frac{v}{4 H R T \sqrt{k_{\mathrm{aq}}^{\mathrm{I}} D_{\mathrm{aq}}}},
$$

where $\alpha$ denotes the accommodation coefficient, i.e. the probability that the molecule accommodates and dissolves in the vicinity of the surface, also commonly denoted as mass accommodation coefficient. $\Gamma_{\mathrm{rxn}}$ is the probability of reaction in the liquid phase. $\mathrm{H}$ denotes the Henry's Law coefficient (HOBr: $>1.9 \times 10^{3}$ (Blatchley et al., 1992) and $6.1 \times 10^{3} \mathrm{M} \mathrm{atm}^{-1}$ (Frenzel et al., 1998), $\mathrm{R}$ the gas constant, $D_{\text {aq }}$ the diffusion coefficient of $\mathrm{HOBr}$ in the liquid phase, and $k_{\mathrm{aq}}^{\mathrm{I}}$ the first order loss rate constant of $\mathrm{HOBr}$ in the liquid phase.

Aside from two studies of $\mathrm{HOBr}$ uptake on bromide doped ice (Abbatt, 1994; Kirchner et al., 1997) data on the heterogeneous chemistry of reaction (1) are very scarce. In their modelling study, Sander and Crutzen (1996) used an estimated value of 0.056 for the accommodation coefficient, $\alpha$, of $\mathrm{HOBr}$ on deliquescent sea-salt to calculate $\gamma_{\text {upt }}$ as no experimental value was available. Mochida et al. (1998) found an upper limit for $\gamma_{\text {upt }}$ of 0.18 on solid $\mathrm{KBr}$, suggesting that this value also sets a lower limit to $\alpha$, for, however, a dry bromide surface. Abbatt and Waschewsky (1998) for the first time measured the uptake coefficient of $\mathrm{HOBr}$ to deliquescent $\mathrm{NaCl}$ aerosols. On acidified $\mathrm{NaCl}, \gamma_{\text {upt }}$ was between 0.1 and 0.2 , at the limit where under their experimental conditions $\gamma_{\text {upt }}$ became controlled by diffusion, whereas on unbuffered $\mathrm{NaCl} \gamma$ upt was about $10^{-3}$, clearly due to consumption of the available acidity in the aerosol. From that study, a lower limit to the accommodation coefficient of 0.2 has been suggested. Also in the experiments by Fickert et al. (1999) diffusion controlled uptake in cylindrical flow tube geometry was observed. This, on the other hand, led to an experimental value for the diffusion coefficient in the gas-phase, allowing a more reliable assessment of $\Gamma_{\text {diff }}$.

Therefore, a reliable measurement of the presumably high accommodation coefficient on deliquescent sea salt is still missing. The requirements for such an experiment are relatively strict: the uptake should not be limited by diffusion. Due to the high vapour pressure of water, the loss to the walls of a cylindrical flow tube remains diffusion limited. Therefore, an experiment with deliquescent particles in gassuspension at atmospheric pressure is appropriate if the particle diameter is small enough so that $1 / \Gamma_{\text {diff }}$ remains small, i.e. clearly in the sub-micron range. On the other hand, due to the extremely low aerosol mass in that size range, it is likely that a substantial fraction of the reactants (bromide or protons) is depleted before measurable amounts of $\mathrm{HOBr}$ are lost from the gas-phase. Therefore, using more classical analytical instrumentation, the measured uptake coefficient might be limited by the availability of the reactants, but not by the accommodation coefficient. This has been demonstrated by Abbatt and Waschewsky (1998) showing that the uptake coefficient of $\mathrm{HOBr}$ rapidly dropped on deliquescent $\mathrm{NaCl}$ particles, when the particles were not buffered to provide enough protons. One way out of this sensitivity limitation is by using a radioactive isotope. In previous studies using ${ }^{13} \mathrm{~N}$, the potential of this method to investigate the heterogeneous chemistry of nitrogen oxides at very low concentrations has been shown (Kalberer et al., 1996; Ammann et al., 1998; Kalberer et al., 1999; Ammann, 2001; Arens et al., 2001). Recently, an approach to generate short-lived bromine isotopes in defined chemical form in the gas-phase has been developed (Wachsmuth et al., 2000; Wachsmuth et al., 2002), based on a gas-jet facility mounted at the Swiss Spallation Neutron Source (SINQ) at Paul Scherrer Institute. In a 


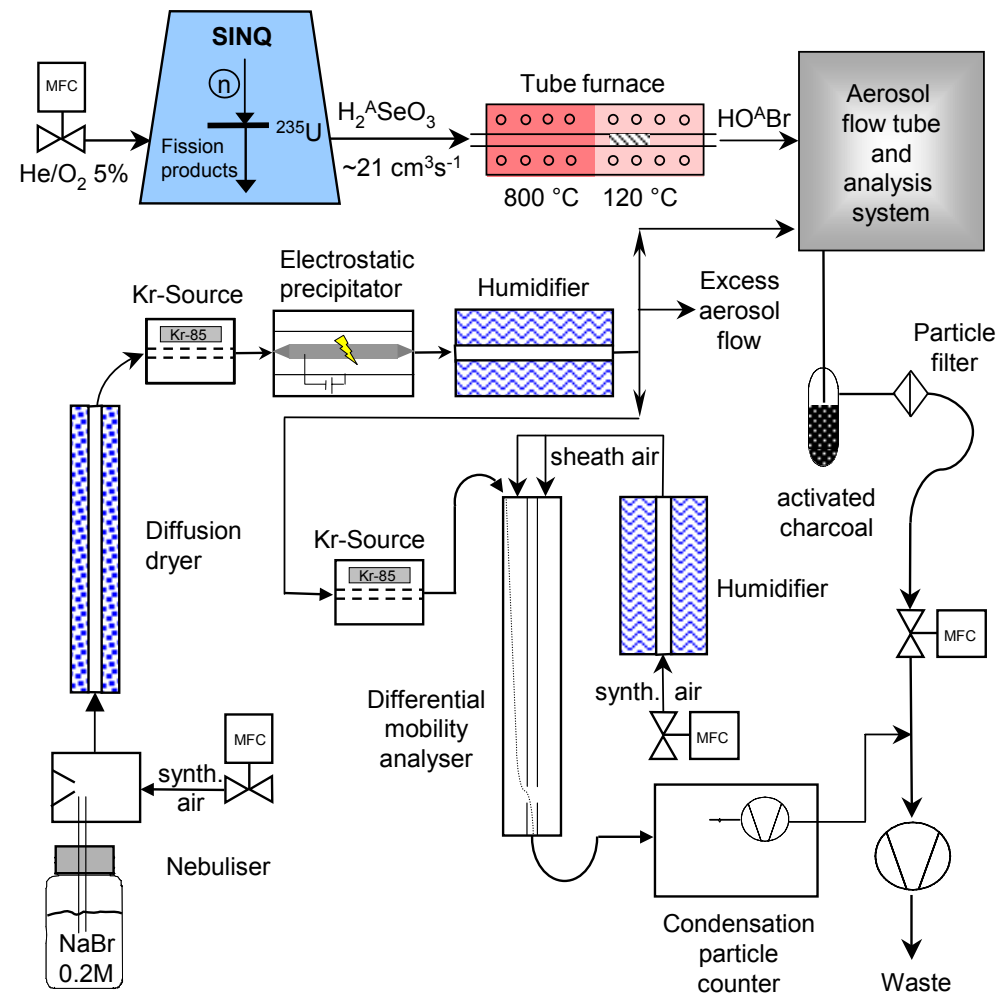

Fig. 1. Set-up of the on-line $\mathrm{HO}^{\mathrm{A}} \mathrm{Br}$ source and the $\mathrm{NaBr}$ aerosol generator, coupled together to measure uptake of $\mathrm{HOBr}$ on the aerosol in flow tube experiments. Mass flow controllers are denoted by MFC, for further details see text.

campaign at this facility, reported here, $\mathrm{HO}^{\mathrm{A}} \mathrm{Br}(\mathrm{A}=83-86)$ was allowed to react with deliquescent $100 \mathrm{~nm}-\mathrm{NaBr}$ particles in gas suspension. The $\mathrm{HOBr}$ concentration of a few hundred molecules per $\mathrm{cm}^{3}$ was low enough and the aqueous phase removal fast enough, so that the uptake was only limited by the accommodation coefficient.

\section{Experimental}

\subsection{Generation of labelled $\mathrm{HOBr}$}

The system delivering short-lived bromine isotopes as gasphase molecules has been described in detail elsewhere (Wachsmuth et al., 2000; Wachsmuth et al., 2002). Briefly, $\mathrm{HO}^{83-86} \mathrm{Br}$ was produced as following. At the Swiss Spallation Neutron Source (SINQ) at Paul Scherrer Institute (PSI), a small amount of ${ }^{235} \mathrm{U}$ was irradiated with thermal neutrons resulting in fission of ${ }^{235} \mathrm{U}$ and delivering several selenium isotopes (among many other nuclides), which were emitted into a carrier gas $\left(5 \% \mathrm{O}_{2}\right.$ in $\mathrm{He}$, humidified to $10 \%$ relative humidity). The Se isotopes form selenous acid molecules, which were swept to the laboratory, where they were thermally decomposed to elemental selenium and probably $\mathrm{SeO}_{2}$ and deposited on quartz at $130^{\circ} \mathrm{C}$ (see Fig. 1). The Se isotopes decay into their daughter bromine isotopes. This $\beta^{-}$ decay, in which an electron with $1.4 \mathrm{MeV}$ energy is emitted, certainly results in a highly excited $\mathrm{Br}^{+}$ion, the fate of which is not known in detail. As the bromine isotope could only be released from the quartz surface, when $\mathrm{O}_{2}$ was added, we believe that the initial molecule might have been $\mathrm{BrO}$ or $\mathrm{OBrO}$ which react to $\mathrm{HOBr}$ in a second step. It is very unlikely, that $\mathrm{Br}$ atoms may have escaped our experimental set-up. The large quartz surface also seemed to be essential possibly as substrate for $\mathrm{H}_{2} \mathrm{O}$ adsorption providing a way for more efficient reaction of $\mathrm{OBrO}$ with $\mathrm{H}_{2} \mathrm{O}$. Also, the electron emitted might have induced a high density of ions and radicals $\left(\mathrm{O}, \mathrm{OH}, \mathrm{HO}_{2}\right)$ in the immediate vicinity of the bromine isotope promoting the fast conversion of the primary species to $\mathrm{HOBr}$ (Wachsmuth et al., 2002). The following checks were made to confirm the chemical identity of the $\mathrm{Br}$ isotopes as $\mathrm{HOBr}$ : Macroscopic amounts of $\mathrm{HOBr}$ were produced according to three different methods (Dancer, 1863; Noszticzius et al., 1982; Koga et al., 1989; Lock et al., 1996; Allanic et al., 1997), and the batch controlled by its UV/VIS spectrum (Orlando and Burkholder, 1995). HOBr, synthesised in the on-line method described by Koga et al. (1989) was passed at a slow rate over quartz in a thermostated bath. The temperature $(203 \mathrm{~K})$ at which $\mathrm{HOBr}$ was condensing was consistent with the deposition temperature $(188 \mathrm{~K})$ of $\mathrm{HO}^{\mathrm{A}} \mathrm{Br}$ in the temperature gradient of a thermochromatography experiment (Eichler et al., 1995). 
Whereas the former is related to the sublimation enthalpy of $\mathrm{HOBr}$, the latter is related to the adsorption enthalpy of individual $\mathrm{HO}^{\mathrm{A}} \mathrm{Br}$ molecules on an inert surface and depends on the gas flow rate and pressure at which the experiment is run (Eichler, 1977; Gäggeler et al., 1986). This thermochromatography experiment also showed that only one species was formed. The adsorption enthalpy derived indicated a relatively polar species able to form hydrogen-bonds to a polar surface (Wachsmuth et al., 2002). Any contamination by isotopes in the form of for example $\mathrm{HBr}$ that could have been formed due to the radical chemistry mentioned above or due to trace amounts of hydrogen impurities in the carrier gas would have been observed as deposition at much higher temperature in the thermochromatography experiment, as single $\mathrm{HBr}$ molecules are easily absorbed into water adsorbed on any surface.

The system was operated on-line, and steady state concentrations of the bromine isotopes in the flow system were established according to the half-lives of the generating Se isotopes. From the measurement of the count-rates of either the decay precursor selenium or directly the ones of bromine nuclides (Wachsmuth et al., 2000, 2002), the steady state concentrations of $\mathrm{HO}^{83} \mathrm{Br}, \mathrm{HO}^{84} \mathrm{Br}$, and $\mathrm{HO}^{86} \mathrm{Br}$ were 245,12 , and 13 molecules $\mathrm{cm}^{-3}$, respectively. For technical reasons, the decay rate of ${ }^{85} \mathrm{Se}$ could not be measured, but was estimated from the known fission yield. Br isotopes with masses below 83 or above 86 can be neglected. Summing up, the overall $\mathrm{HOBr}$ concentration was about 280 molecules $\mathrm{cm}^{-3}$.

\subsection{Generation of deliquescent $\mathrm{NaBr}$ aerosols}

A $0.2 \mathrm{M}$ sodium bromide solution (Fluka 71329 MicroSelect $\geq 99.5 \%)$ was nebulised in synthetic air $\left(20 \% \mathrm{O}_{2}\right.$ in $\mathrm{N}_{2}$, Sauerstoffwerke Lenzburg) using a homemade nebuliser with a pressure drop of 1.6 bar. The resulting droplets were dried in a diffusion dryer, mounted directly on top of the nebuliser, consisting of a tubular reticule surrounded by silica gel and reducing the relative humidity in the gas to below 5\%. Downstream (see Fig. 1), the particles passed an ${ }^{85} \mathrm{Kr}$ source (a bipolar ion source) to establish an equilibrium charge distribution. An electrostatic precipitator removed all charged particles so that only neutral particles were passing on through the experiment to avoid any uncontrollable losses of charged particles in isolating, but chemically inert tubing. The aerosol flow was humidified by passing the gas through an $8 \mathrm{~cm}$ long, $0.6 \mathrm{~cm}$ i.d., permeable PTFE membrane (Goretex $®$ ) tube immersed in water, of which the temperature could be controlled. The relative humidity was measured with a capacitance humidity sensor (Rotronic) and could be adjusted to between $20 \%$ and $90 \%$ at room temperature. For the experiments with the deliquescent particles, it was adjusted to $85 \%$, before this gas flow was admixed to the comparably dry gas containing labelled $\mathrm{HOBr}$.

Before the aerosol flow was admitted to the flow tube, a part of it was passing a scanning mobility particle sizer (SMPS), consisting of a ${ }^{85} \mathrm{Kr}$ source, a differential mobility analyser (DMA) and a condensation particle counter (CPC, TSI 3022). During the uptake experiments, the humidity of the sheath air flow in the DMA was adjusted to the same humidity as in the mixed gas of the flow tube so that the size of the deliquescent particles in the DMA was identical to that in the flow tube. The mobility diameter based surface area obtained by this device was used to calculate the gas-kinetic collision rate to the particles.

\subsection{Reaction of labelled $\mathrm{HOBr}$ with sodium bromide aerosols}

The atmospheric pressure aerosol flow tube was made of perfluoroalkoxy copolymer (PFA) with an inner diameter of $0.8 \mathrm{~cm}$. The reaction volume and therewith the reaction time could be varied by changing the position of an inner tube ('injector') with an inner diameter of $0.44 \mathrm{~cm}$, also made of PFA, through which the flow containing $\mathrm{HOBr}\left(21 \mathrm{~cm}^{3} \mathrm{~s}^{-1} \mathrm{STP}\right.$ (standard temperature and pressure) of $5 \% \mathrm{O}_{2}$ in $\mathrm{He}, \sim 10 \%$ relative humidity) was admitted. To facilitate mixing, the inner tube was plugged, and the gas exited through small holes near the tube end. The aerosol flow $\left(10.4 \mathrm{~cm}^{3} \mathrm{~s}^{-1} \mathrm{STP}\right.$ of $20 \% \mathrm{O}_{2}$ in $\mathrm{N}_{2}, 85 \%$ relative humidity) entered the reaction tube through a T-connector by passing the annulus formed between the injector and the flow tube walls. In most of the experiments, the relative humidity of the flow tube at room temperature $\left(23 \pm 2^{\circ} \mathrm{C}\right)$ was $37 \%$.

The analysis made use of fast isotope exchange between $\mathrm{Br}_{2}(\mathrm{aq})$ and $\mathrm{Br}_{(\mathrm{aq})}^{-}$for measuring the uptake to deliquescent particles (see below). Therefore, the main task consisted of separating $\mathrm{HOBr}_{(\mathrm{g})}$ from the particles using a denuder and detecting the activity of the bromine isotopes associated with the coated denuder wall for $\operatorname{HOBr}(\mathrm{g})$ and that associated with the particles retained on a impregnated filter, respectively (see Fig. 2). As the reaction was very fast, a very fast separation was necessary to achieve a reasonable time resolution. A specially developed parallel glass plate denuder with $0.1 \mathrm{~cm}$ spacing and $2.6 \mathrm{~cm}$ width was used (Ammann, 2001) resulting in a very narrow deposition zone of $\mathrm{HOBr}$ and a time resolution of about $10 \mathrm{~ms}$, while the aerosol particles passed with $100 \% \pm 5 \%$ penetration efficiency as checked using the SMPS system. For an efficient, diffusion controlled absorption of HOBr molecules in the denuder, the glass plates were coated with tetrabutylammonium hydroxide (TBAH, Fluka 86882 , pract. $~ 25 \%$ in methanol) (Gandrud and Lazrus, 1983; Sedlacek et al., 1984). The particle filter behind the denuder was a disc of compressed glass fibers (Schleicher \& Schuell GF 6) retaining more than $99 \%$ of the particles in the submicron size range. The detection of labelled $\mathrm{HOBr}$ was restricted to the determination of ${ }^{84} \mathrm{Br}$ and ${ }^{86} \mathrm{Br}$ isotopes, and was realized by $\gamma$ spectroscopy using the lines at $881.6 \mathrm{keV}$ and $1564.9 \mathrm{keV}$, respectively, with a high purity germanium (HPGe) detector (Canberra) mounted to both the denuder plates and the filter. Absolute calibration was performed for both geometries using ${ }^{88} \mathrm{Y}$ and ${ }^{54} \mathrm{Mn}$ as standard radiation sources. Better counting statistics was obtained when working with ${ }^{84} \mathrm{Br}$; however, due to the half-life of $31.8 \mathrm{~min}$, integration intervals were much longer than with ${ }^{86} \mathrm{Br}$ with a halflive of $56 \mathrm{~s}$. Therefore, separate experiments with both nuclides were performed.

For comparison with other experiments on solid bromide surfaces (Mochida et al., 1998) a few experiments were performed under dry conditions with solid $\mathrm{NaBr}$ particles (see below). Under these conditions, the isotope exchange is not effective due to the absence of sufficient amounts of aqueous bromide, and uptake 


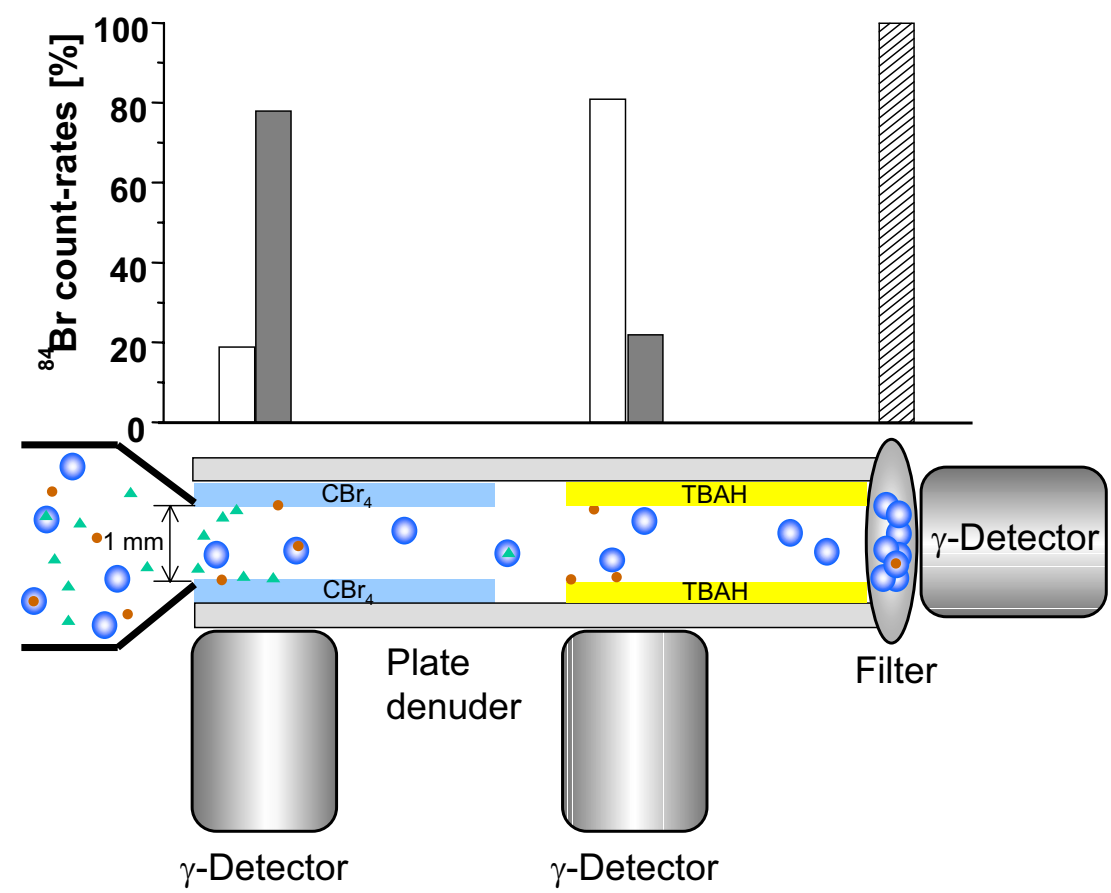

Fig. 2. Analytical set-up for the determination of $\mathrm{Br}$ count-rates associated with $\mathrm{HOBr}_{(\mathrm{g})}, \mathrm{Br}_{2}(\mathrm{~g})$ and the aerosol, consisting of a portable $\gamma$-detector that can be placed at the denuder system adjacent to the plates coated with $\mathrm{CBr}_{4}$ and $\mathrm{TBAH}$ to absorb $\mathrm{Br} 2(\mathrm{~g})$ and $\mathrm{HOBr}(\mathrm{g})$, respectively, or at an impregnated filter, respectively. The bars indicate the normalised count-rates measured by the detector and corrected for counting efficiency (empty bars: in absence of $\mathrm{NaBr}$ aerosol particles; grey bars: in presence of dry $\mathrm{NaBr}$ particles; hatched bar: in presence of deliquescent $\mathrm{NaBr}$ particles) for experiments with $3.3 \mathrm{~s}$ (dry case) and $0.9 \mathrm{~s}$ (deliquescent case) reaction time.

of $\mathrm{HOBr}$ results in the release of labelled $\mathrm{Br}_{2}$. For this case, a reasonable separation of $\mathrm{HOBr}$ from $\mathrm{Br}_{2}$ was achieved by mounting an additional denuder in front of the TBAH denuder, which was coated with carbon tetrabromide $\left(\mathrm{CBr}_{4}\right)$ (Fluka 86770 , purum) by applying $\mathrm{CBr}_{4}$, dissolved in carbon disulfide (Merck 102214 , p.a.) to the glass plates. The use of $\mathrm{CBr}_{4}$ as material to absorb $\mathrm{Br}_{2}$ has not been reported previously. It was used as low-volatile analogue to $\mathrm{CCl}_{4}$ in which $\mathrm{Br}_{2}$ is highly soluble.

As in the denuders $\operatorname{HOBr}_{(\mathrm{g})}$ was rapidly separated from the aerosol, simply dissolved but not reacted $\operatorname{HOBr}_{(\mathrm{aq})}$ would have been stripped off the particles during the residence time in the denuder and would not have contributed to the measured uptake. Therefore, as long as no isotope exchange occurs between $\operatorname{HOBr}_{(\mathrm{aq})}$ and bromide, the uptake must be driven entirely by reaction, so that the mass accommodation coefficient can be measured using the present set-up.

\section{Results and discussion}

In contrast to pure $\mathrm{NaCl}$ (Weingartner et al., 1995; Luna et al., 1998; Cziczo and Abbatt, 2000), the deliquescence and efflorescence properties of the mixed sea salt particles, and also of $\mathrm{NaBr}$, have not been well documented. Malvestuto and Ascoli (2001) estimated the deliquescence humidity of $\mathrm{NaBr}$ particles $100 \mathrm{~nm}$ in diameter to around $58 \%$ from the known activity coefficients. In the present experiment, the humidity in the $\mathrm{HOBr}$ flow was kept low to avoid its retention on tube walls before the flow tube. Thus, the final humidity in the flow tube was much lower than in the aerosol flow. Therefore it must be assured that the particles, initially humidified to $85 \%$, remain in their deliquescent state when the humidity is lowered to $37 \%$. First, the humidifier in the aerosol flow and in the sheath air flow of the DMA were bypassed to obtain the size of the 'dry' particles at around $6 \%$ relative humidity with a modal diameter of $35 \mathrm{~nm}$ (Fig. 3). When the humidity in both flows was increased to $37 \%$, adsorption of low amounts of water did not lead to a measurable size change, the particles did clearly not deliquesce. When the humidity was increased to $85 \%$ (for both aerosol and DMA sheath air) the particles got deliquescent and increased their size accordingly. Once the particles had been equilibrated at $85 \%$, they reduced their size, when the humidity was decreasing to $37 \%$ again by dilution with dry gas. However, they did not shrink to the dry size, but remained clearly deliquescent. Thus, under the conditions adopted below for most experiments at $37 \%$ relative humidity, the particles were supersaturated bromide solutions.

A few experiments were performed with dry particles. The interaction time in the flow tube was adjusted to $3.27 \mathrm{~s}$, and the relative humidity was $6 \%$ at room temperature. First, the aerosol was switched off, and the activity associated with absorption of $\mathrm{HO}^{84} \mathrm{Br}$ on the TBAH denuder was measured. Retention of $\mathrm{HOBr}$ on $\mathrm{CBr}_{4}$ led also to a significant signal on the first denuder (Fig. 2). As the flow of ${ }^{\mathrm{A}} \mathrm{Br}$ was not always constant due to variations in the neutron source, all measured activities are reported in normalised form. Typical counting rates measured at the detector were between 0.2 and $1.0 \mathrm{~s}^{-1}$, with a detection limit of $0.1 \mathrm{~s}^{-1}$, for both isotopes. After "switching on" the aerosol (by opening the supply of bromide 


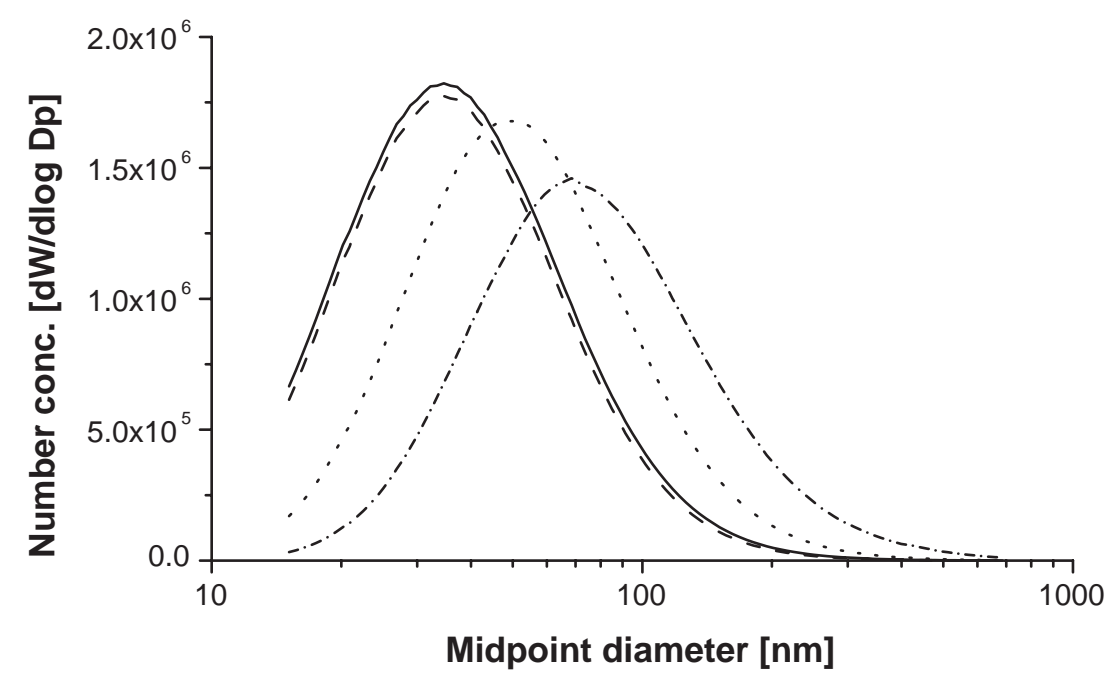

Fig. 3. The change of the number size distribution with humidity for dry and deliquescent $\mathrm{NaBr}$ particles. At $6 \%$ r.h. a modal diameter of $35 \mathrm{~nm}$ results (solid line), which not measurably changes after increasing the humidity to $37 \%$ (dashed line). Deliquescence is obviously reached at $85 \%$ r.h. (dash dotted line) and remains after decreasing the humidity again to $37 \%$ (dotted line). Due to varying losses in these different configurations, the number concentrations are not matching.

solution to the nebuliser), all ${ }^{84} \mathrm{Br}$ activity was associated with the $\mathrm{CBr}_{4}$ denuder, clearly indicating complete conversion of $\mathrm{HO}^{84} \mathrm{Br}$ to ${ }^{84} \mathrm{BrBr}$. It also demonstrates the ability of the relatively unpolar $\mathrm{CBr}_{4}$ to retain $\mathrm{Br}_{2}$ and to only weakly interact with $\mathrm{HOBr}$. $\mathrm{Br}_{2}$ would also be efficiently absorbed by TBAH (Sedlacek et al., 1984). Based on a few more experiments not shown here, and the total aerosol surface area in the flow tube of $1.10 \times 10^{-4} \mathrm{~cm}^{2} \mathrm{~cm}^{-3}$, an uptake coefficient, $\gamma_{\text {upt }}$, of at least 0.5 was estimated. This is still higher than the value observed by Mochida et al. (1998) at the lowest concentration. At $6 \%$ relative humidity, adsorption of water at defect sites of the crystalline $\mathrm{NaBr}$ surface may already lead to partial solvation of bromide available for reaction (1). Indications of ionic species on $\mathrm{NaCl}$ surfaces were found based on spectroscopic evidence (Beichert and Finlayson-Pitts, 1996) and on results of the reaction with $\mathrm{HNO}_{3}$ (Davies and Cox, 1998) far below the deliquescence humidity of $\mathrm{NaCl}$. Whether under these conditions the $\mathrm{NaBr}$ substrate can provide the acidity necessary for reaction (1) as in the case of an aqueous solution, remains an open question.

More detailed kinetic experiments were performed with deliquescent particles in the flow tube at $37 \%$ relative humidity and room temperature. Again, for a reaction time of $0.90 \mathrm{~s}$, first the steady state activities at the denuders and the filter were observed while no aerosol particles were present (see Fig. 2). When then the aerosol was "switched on", the activity on the filter increased while that on the denuders decreased to below detection limits, clearly indicating complete uptake of $\mathrm{HO}^{\mathrm{A}} \mathrm{Br}$ into the particles. Fast isotope exchange between $\mathrm{Br}_{2}$ and aqueous bromide keeps the ${ }^{\mathrm{A}} \mathrm{Br}$ isotope as bromide in solution and results in activity on the particle filter, and non-labelled $\mathrm{Br}_{2}$ is released:

$\mathrm{HO}^{\mathrm{A}} \mathrm{Br}+\mathrm{Br}^{-}+\mathrm{H}^{+} \longrightarrow{ }^{\mathrm{A}} \mathrm{BrBr}+\mathrm{H}_{2} \mathrm{O}$

${ }^{\mathrm{A}} \mathrm{BrBr}+\mathrm{Br}^{-} \longrightarrow \mathrm{Br}_{2}+{ }^{\mathrm{A}} \mathrm{Br}$

The kinetics of the analogous isotope exchange between $\mathrm{Cl}_{2}$ in halogenide solutions was studied by Long and Olson (1936) and reported by Wahl and Bonner (1951). This isotope exchange is due to the equilibrium

$\mathrm{Br}_{2}+\mathrm{Br}^{-} \leftrightarrow \mathrm{Br}_{3}^{-}$

with an equilibrium constant of $16.1 \mathrm{M}^{-1}$ (Liu and Margerum, 2001), and forward and reverse rate constants are $5.5 \times 10^{9} \mathrm{M}^{-1} \mathrm{~s}^{-1}$ and $5 \times 10^{7} \mathrm{~s}^{-1}$, respectively (Ruasse et al., 1986). Therefore, in a saturated bromide solution $(48.6 \% \mathrm{wt} .=4.72 \mathrm{M}$, Lide, 1998$)$, the characteristic time for exchange was much faster than that of separation of gas-phase $\mathrm{Br}_{2}$ from the particles $\left(10^{-3} \mathrm{~s}\right)$ or even faster than that of diffusion out of the liquid particle $\left(10^{-5} \mathrm{~s}\right.$, estimated from $d_{\mathrm{p}}^{2} / D_{\mathrm{aq}}$ ). Thus, each ${ }^{\mathrm{A}} \mathrm{Br}$ detected on the particles has gone through the complete reaction in the aqueous phase of the deliquescent particles. When the $\gamma$-detector for $\mathrm{HO}^{\mathrm{A}} \mathrm{Br}$ was placed further downstream along the denuder plate, no signal from ${ }^{\mathrm{A}} \mathrm{Br}$ was observed indicating that not a significant fraction of labelled $\mathrm{HOBr}$ or $\mathrm{Br}_{2}$ was slowly desorbing from the particles on the time scale of a few tens of milliseconds after the main part of $\operatorname{HOBr}(\mathrm{g})$ has been removed from the gas phase.

As we could not observe the few non-labelled $\mathrm{Br}_{2}$ molecules on the $\mathrm{CBr}_{4}$ denuder, for all other experiments described below, the $\mathrm{CBr}_{4}$ denuder was omitted to improve the time resolution and the counting statistics for $\mathrm{HO}^{\mathrm{A}} \mathrm{Br}$ on the TBAH denuder. Figure 4 shows the result of a number of experiments at different reaction times, showing the decrease of activity at the TBAH denuder associated with $\mathrm{HOBr}_{(\mathrm{g})}$, and the increase of activity on the particle filter associated with reacted $\mathrm{HOBr}$. The average aerosol surface to volume ratio was $1.25 \times 10^{-3} \mathrm{~cm}^{2} \mathrm{~cm}^{-3}$. For each data point a reference experiment without aerosol was performed, in which the counting rate at the denuder downstream of the flow tube was compared with that measured when the flow tube was bypassed, to check for losses of $\mathrm{HO}^{\mathrm{A}} \mathrm{Br}$ on the flow tube walls due to deposition of particles. In the latter case, the PFA tube was exchanged. A new PFA tube did not show any detectable loss or retention of $\mathrm{HO}^{\mathrm{A}} \mathrm{Br}$. 


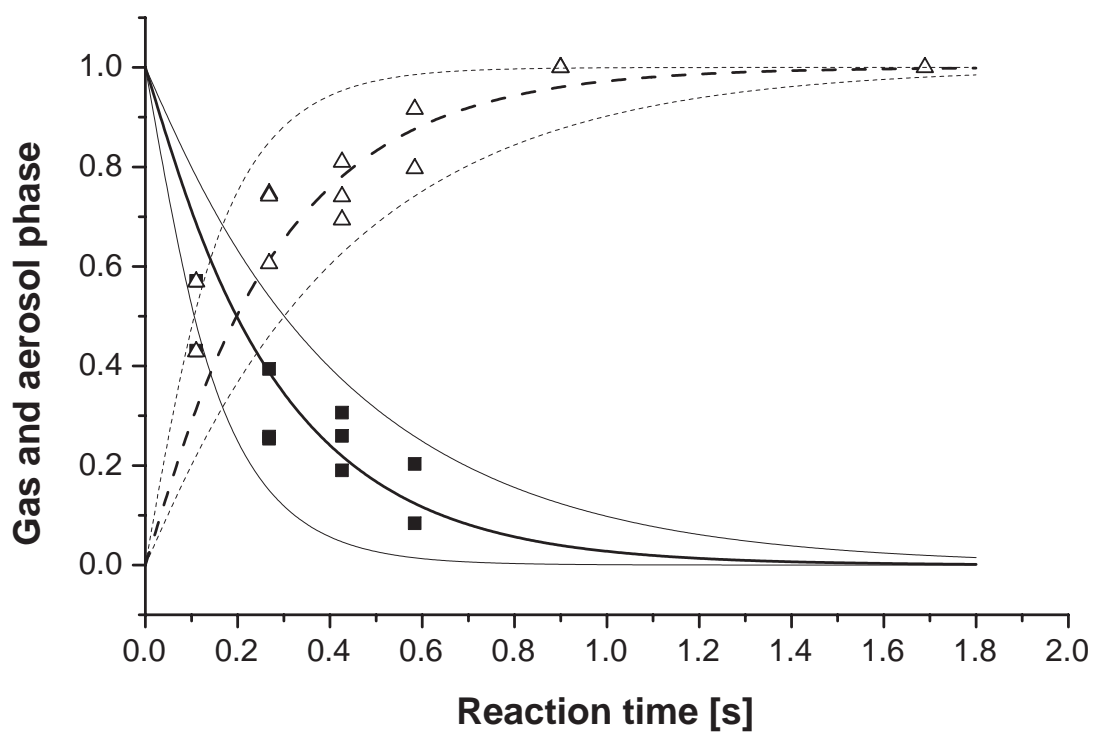

Fig. 4. Uptake of $\mathrm{HOBr}$ to deliquescent $\mathrm{NaBr}$ particles for reaction times in the range of 0.1 to $1.7 \mathrm{~s}$. With increasing reaction time, the $\mathrm{Br}$ activity on the particles increases (open triangle), which is measured on the filter. The activity associated with $\mathrm{HOBr}(\mathrm{g})$ decreases with increasing reaction time (plain squares). The bold lines (solid: $\mathrm{HO}^{\mathrm{A}} \mathrm{Br}(\mathrm{g})$, dashed: ${ }^{\mathrm{A}} \mathrm{Br}^{-}(\mathrm{aq})$ ) are a fit of a mass transfer calculation based on the formalism explained in the text to the experimental data. The thin lines are the corresponding curves for $\gamma$ upt of 0.3 and 1.0 , for reference.

The net first order loss rate of $\mathrm{HOBr}_{(\mathrm{g})}$ derived from a fit to the data shown in Fig. 4 was $4.2 \mathrm{~s}^{-1}$ resulting in a $\gamma_{\text {net }}$ of 0.53 (Eq. 3). For such high net uptake, a small correction for diffusion according to Eq. (4) might be adequate even though the particles were small. As the diffusion coefficient of $\mathrm{HOBr}$ in the gas-mixture of the flow tube, composed of $\mathrm{He}, \mathrm{O}_{2}, \mathrm{~N}_{2}$ and $\mathrm{H}_{2} \mathrm{O}$, was not readily available, the diffusion was calculated from the diffusion coefficients of each binary mixture:

$\frac{1}{D_{\mathrm{tot}}}=\frac{p_{\mathrm{He}}}{D_{\mathrm{He}}^{\mathrm{HOBr}}}+\frac{p_{\mathrm{O}_{2}}}{D_{\mathrm{O}_{2}}^{\mathrm{HOBr}}}+\frac{p_{\mathrm{N}_{2}}}{D_{\mathrm{N}_{2}}^{\mathrm{HOBr}}}+\frac{p_{\mathrm{H}_{2} \mathrm{O}}}{D_{\mathrm{H}_{2} \mathrm{O}}^{\mathrm{HOBr}}}$

resulting in $D_{\text {tot }}=0.263 \mathrm{~cm}^{2} \mathrm{~s}^{-1} . \quad p_{\mathrm{X}}$ is the partial pressure of $\mathrm{X}$ [Torr] and $D_{\mathrm{X}}^{\mathrm{HOBr}}$ the diffusion coefficient of $\mathrm{HOBr}$ in $\mathrm{X}$ [Torr $\mathrm{cm}^{2} \mathrm{~s}^{-1}$ ]. The $D_{\mathrm{X}}^{\mathrm{HOBr}}$ were estimated according to the first approximation reported by Hirschfelder et al. (1954) for the diffusion coefficient of gas 1 in gas 2 :

$$
\begin{aligned}
& {\left[D_{12}\right]_{\text {1.approx. }}=2.628 \cdot 10^{-3}} \\
& \quad \frac{\sqrt{T^{3}\left(M_{1}+M_{2}\right) / 2 M_{1} M_{2}}}{p \sigma_{12}^{2} \Omega_{12}^{(1,1)^{*}}\left[T_{12} *\right]}, \text { in }^{2} \mathrm{~cm}^{-1}
\end{aligned}
$$

where $T$ is temperature [K], $M_{1}$ is molecular mass of $\mathrm{HOBr}$ and $M_{2}$ of the transport gas component, $p$ is the pressure [atm], $\sigma_{12}$ is the average of the collision diameters of the corresponding molecule pair (Hirschfelder et al., 1954; Lide, 1998; Abbatt, 2001), and $\Omega$ is a tabulated function of the Lennard-Jones potential (Hirschfelder et al., 1954). For $\mathrm{He}, \mathrm{N}_{2}$, and $\mathrm{H}_{2} \mathrm{O}$ these values for $D_{\mathrm{He}}^{\mathrm{HOBr}}, D_{\mathrm{N}_{2}}^{\mathrm{HOBr}}$ and $D_{\mathrm{H}_{2} \mathrm{O}}^{\mathrm{HOBr}}$ are comparable with those measured by Fickert et al. (1999). Based on the diffusion coefficient obtained here and Eq. (4), $1 / \Gamma_{\text {diff }}$ was 0.071 . Therefore, the uptake coefficient, $\gamma_{\text {upt }}$, becomes
0.55 , which already indicates that uptake might have been accommodation limited. Whether the resistance to reaction in the liquid phase limited the uptake is mainly determined by the first order loss rate in the liquid phase due to the equilibrium reaction (1), with forward and reverse rate constants $1.6 \times 10^{10} \mathrm{M}^{-2} \mathrm{~s}^{-1}$ and $110 \mathrm{~s}^{-1}$, respectively (Eigen and Kustin, 1962). The major uncertainty with assessing this rate is the $\mathrm{H}^{+}$concentration in the deliquescent particles under our experimental conditions. The $p_{\mathrm{K}_{\mathrm{a}}}$ of the cation acid $\left(\mathrm{Na}^{+}\right)$is 14.8 (Lide, 1998) and the $p_{\mathrm{K}_{\mathrm{b}}}$ of the anion base $\left(\mathrm{Br}^{-}\right)$ is $\sim 20$ (Schröter et al., 1994), from which we would expect that the $\mathrm{NaBr}$ solution should chemically react acidic. Assuming that the main acidifying gas in our system were traces of $\mathrm{CO}_{2}$, we estimated the $\mathrm{pH}$ of our particles to be around 6 . Using this value and the bromide activity $\left(\alpha_{\mathrm{NaBr} \text { (sat })}=0.56-0.57\right.$, Resnik et al., 1984) we estimated the $\mathrm{H}^{+}$concentration to about $2 \times 10^{-6} \mathrm{M}$. Due to reaction with the very few $\mathrm{HOBr}$ molecules, the $\left[\mathrm{H}^{+}\right]$concentration was not depleted during reaction. Therefore, we expect the equilibrium for (1) to be far on the right side:

$$
\frac{\left[\mathrm{Br}_{2}\right]}{[\mathrm{HOBr}]}=1.2 \cdot 10^{6} \text {, }
$$

and the first order loss rate $k_{\mathrm{aq}}^{\mathrm{I}}$ becomes about $10^{5} \mathrm{~s}^{-1}$. This leads to a value of $2.4 \times 10^{-2}$ for $1 / \Gamma_{\text {rxn }}$ according to Eq. (6), which is not a significant contribution to $1 / \gamma_{\text {upt }}$. The reacto-diffusive length, i.e. the characteristic distance beyond the surface after which the $\mathrm{HOBr}$ has been lost due to reaction, is on the order of $10^{-6} \mathrm{~cm}$, indicating that under the assumed conditions, $\mathrm{HOBr}$ significantly entered the bulk. The concentration of $\mathrm{HOBr}$ was so low that at most one $\mathrm{HOBr}$ molecule was processed per particle, so that $\mathrm{H}^{+}$was never depleted. We conclude that under our experimental conditions, uptake was limited by an accommodation coefficient, $\alpha$, of about 0.6 . In Fig. 4, the thin lines indicate the calculated uptake for an uptake 

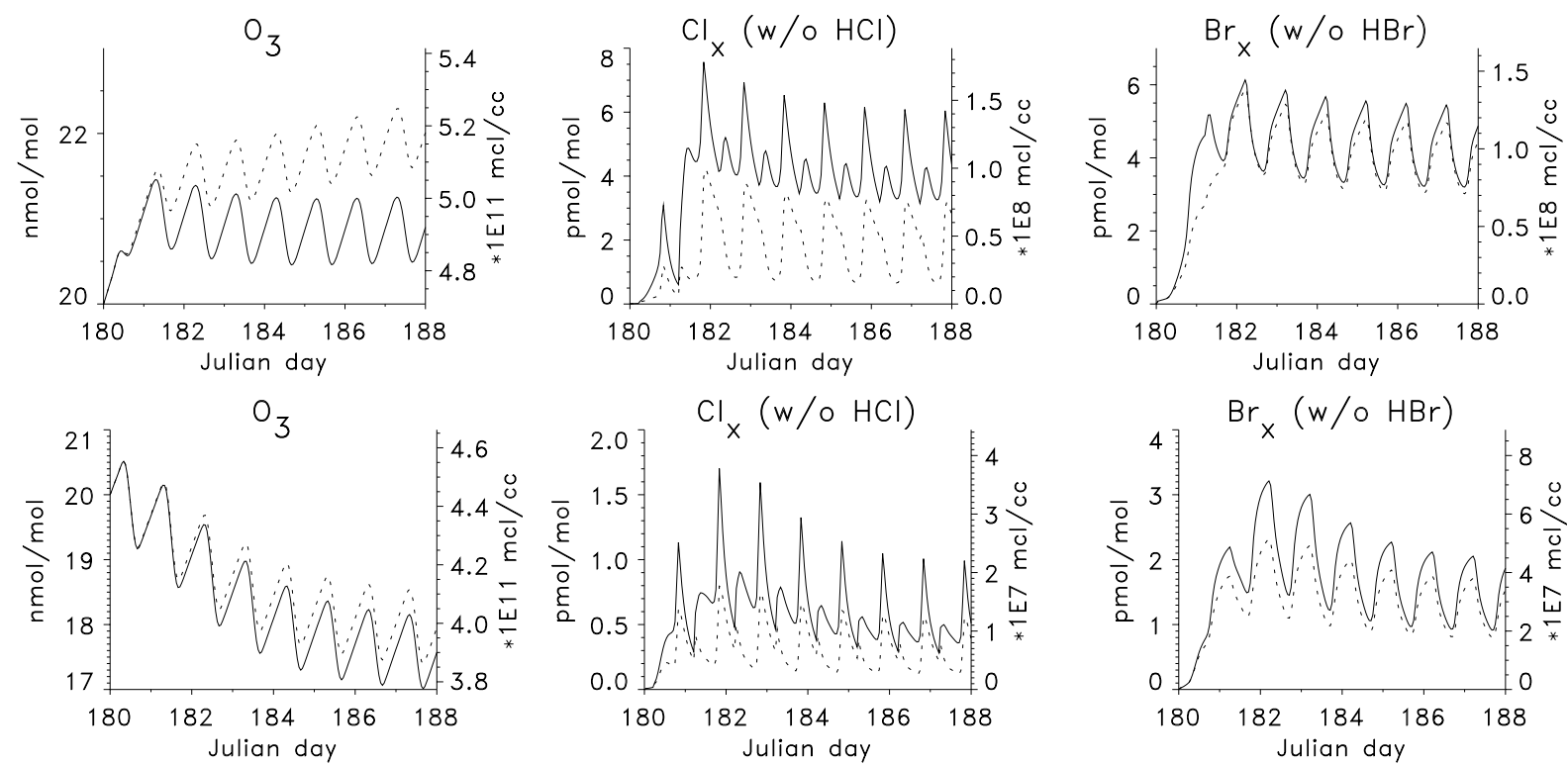

Fig. 5. Results of model runs using the MOCCA box model for the marine boundary layer. Evolution with time of mixing ratios of $\mathrm{O}_{3}, \mathrm{Cl}_{\mathrm{x}}$ and $\mathrm{Br}_{\mathrm{X}}$ (sum of all reactive inorganic gas phase chlorine/bromine species except $\mathrm{HCl} / \mathrm{HBr}$ ) for a scenario with strong bromine activation (a) and moderate bromine activation (b). The solid line is for the cases with $\alpha_{\mathrm{HOBr}}=0.6$ and the dashed line for $\alpha_{\mathrm{HOBr}}=0.06$. Note the different scales on the plots.

coefficient of 1 and 0.3 , respectively, setting the limits within which the experimental data lie. Allowing the diffusion coefficient varying by $30 \%$ would lead to values for $\gamma$ upt between 0.54 and 0.56 . The main error associated with this experiment is coming from estimating the surface area based on the measurements using the SMPS system. Whereas the diameter can be determined to within better than $5 \%$ relative error, a significant error can be induced by nonideal counting efficiency of the CPC, or by a few particles outside the size range covered by the DMA. Allowing the total aerosol surface area varying by $30 \%$, the $\gamma_{\text {upt }}$ values derived from the fit to the data as shown in Fig. 4 would range from 0.42 to 0.80 . Therefore, it seems realistic to report the accommodation coefficient as $0.6 \pm 0.2$, and our result confirms the expectations by Abbatt and Waschewsky (1998). In our analysis, we did not explicitly assess the mixing time between the aerosol and the $\mathrm{HOBr}$ gas flows. The decay and growth curves did not show any significant delay of the reaction. Still, if the characteristic time for mixing would have been as high as 10 percent of the characteristic time for reaction, then we could argue that the accommodation coefficient would be closer to unity than based on our derivation.

The theoretical uncertainty associated with our derivation is related to the parameterization used in Eq. (6), which assumes that the loss to the surface is due to the reaction in the bulk liquid phase. The present experiment does not allow to find evidence for a surface specific reaction which would extend Eq. (6) by a pathway leading from a weakly bound, not dissolved, molecule on the surface directly to $\mathrm{Br}_{2}$ (see Hanson, 1997 for a description of the extended parameterisation). Such surface processes on liquids have been proposed for, e.g. $\mathrm{Br}_{2}, \mathrm{Cl}_{2}$ and $\mathrm{BrCl}$ (Hu et al., 1995; Katrib et al., 2001). In addition, the present approach does not allow to separate the accommodation coefficient into the primary sticking probability, $\mathrm{S}$, i.e. the probability that the molecule is not reflected upon collision, and the rate of solvation (Hanson, 1997, and references therein). However, recent molecular dynamics simulations of the uptake of molecules into aqueous solutions (Taylor et al., 1997; Wilson and Pohorille, 1997) indicate that the accommodation coefficient might often be close to 1 mainly because the excess kinetic energy is easily dissipated into the water and a significant free energy barrier of solvation is lacking, so that hydration of the molecule can occur extremely rapidly. Therefore, whatever the fate of $\mathrm{HOBr}$ is in detail, $\mathrm{HOBr}$ lost from the gas phase seems to have undergone hydration, i.e. accommodation, before reaction to $\mathrm{Br}_{2}$.

\section{Atmospheric implications}

We used the box model MOCCA to estimate the effects of a change of $\alpha_{\mathrm{HOBr}}$ by a factor of 10 because in older versions of MOCCA (Sander and Crutzen, 1996; Vogt et al., 1996) $\alpha_{\mathrm{HOBr}}$ was estimated to be 0.056 . We assume that the accommodation coefficient measured here also holds for a deliquescent sea salt solution. The model treats reactions in the gas and aerosol phase explicitly with a special emphasis on the halogen chemistry in the marine boundary layer. A very comprehensive reaction set is used for sulphate and sea salt aerosols and the coupling of aerosol chemistry with the gas phase. For information on the updated version of the box model MOCCA that is used here see

http: //www.mpch-mainz.mpg.de/ sander/mocca.

We studied the impact of a factor of 10 in the accommodation coefficient for $\mathrm{HOBr}$ in two scenarios. In the first scenario strong bromine activation from the sea salt aerosol takes place, about $95 \%$ of the initial $\mathrm{Br}^{-}$is released to the gas phase. In the second scenario only a moderate bromine activation occurs with a release of about $50 \%$. 
In both scenarios an increase of $\alpha_{\mathrm{HOBr}}$ leads to lower concentrations of $\mathrm{O}_{3}$, but the reasons are different. In the strong activation scenario, an increase in the uptake of $\mathrm{HOBr}$ does not lead to a significant increase in bromine release from the sea salt aerosol, because it already is mainly partitioned to the gas phase. $\mathrm{Br}_{\mathrm{x}}$, the sum of all reactive inorganic gas phase bromine species except $\mathrm{HBr}$, does not change significantly. The change in $\alpha_{\mathrm{HOBr}}$ does, however, lead to an increase in chlorine release from the sea salt aerosol via the reaction

$\mathrm{HOBr}+\mathrm{Cl}^{-}+\mathrm{H}^{+} \rightarrow \mathrm{BrCl}+\mathrm{H}_{2} \mathrm{O}$

and therefore to an increase in $\mathrm{Cl}_{\mathrm{X}}$ (sum of all reactive inorganic gas phase chlorine species except $\mathrm{HCl}$ ). These $\mathrm{Cl}_{\mathrm{X}}$ species (mainly $\mathrm{ClO}$ and $\mathrm{Cl}$ ) are responsible for an increase in $\mathrm{O}_{3}$ loss in this scenario. The initial bromine release from the sea salt aerosol is slowed down a bit in the model run with lower $\alpha_{\mathrm{HOBr}}$ (see Fig. 5a).

In the modest activation scenario a higher $\alpha_{\mathrm{HOBr}}$ does lead to additional release of bromine from the sea salt aerosol. With $\alpha_{\mathrm{HOBr}}=0.06$, about $43 \%$ of the bromine is released to the gas phase, whereas with $\alpha_{\mathrm{HOBr}}=0.6$, about $57 \%$ are lost from the sea salt aerosol. In this scenario both $\mathrm{Cl}_{\mathrm{X}}$ and $\mathrm{Br}_{\mathrm{X}}$ increase in the gas phase when $\alpha_{\mathrm{HOBr}}$ is increased from 0.06 to 0.6 and radicals of both halogens are responsible for the stronger loss of $\mathrm{O}_{3}$ (see Fig. 5b).

\section{Conclusions}

Due to the complexity of the experiment and the limited availability of the large facilities involved, only a limited dataset on the uptake of $\mathrm{HOBr}$ to deliquescent $\mathrm{NaBr}$ aerosol was obtained. Nevertheless, quantitative results were obtained that are, when using conventional experimental methods, only hardly or even not at all accessible. From the experiments presented here, the accommodation coefficient of $\mathrm{HOBr}$ on deliquescent $\mathrm{NaBr}$ was $0.6 \pm 0.2$, which is consistent with the limits set by previous estimates and also adds to current thinking of very high accommodation coefficients of soluble gases on aqueous solution. This is one order of magnitude higher than that used in modeling studies of the marine boundary layer (Sander and Crutzen, 1996; Vogt et al., 1996). The model calculations show that the effect of the increased accommodation coefficient on the marine boundary layer is by slightly increasing the ozone loss and quite significantly increasing chlorine release.

Acknowledgements. This work was supported by the Swiss National Science Foundation. The availability of thermal neutrons at the Swiss Spallation Neutron Source (SINQ) is greatly acknowledged. We thank F. Arens, E. Weingartner, M. Gysel, B. Eichler and R. Eichler for helpful comments.

\section{References}

Abbatt, J. P. D.: Heterogeneous reaction of $\mathrm{HOBr}$ with $\mathrm{HBr}$ and $\mathrm{HCl}$ on ice surfaces at $228 \mathrm{~K}$, Geophys. Res. Lett., 21, 665-668, 1994.

Abbatt, J. P. D. and Waschewsky, G. C. G.: Heterogeneous interactions of $\mathrm{HOBr}, \mathrm{HNO}_{3}, \mathrm{O}_{3}$, and $\mathrm{NO}_{2}$ with deliquescent $\mathrm{NaCl}$ aerosols at room temperature, J. Phys. Chem. A, 102, 3719$3725,1998$.

Abbatt, J. P. D.: Personal Communication, 2001.

Allanic, A., Oppliger, R., and Rossi, M. J.: Real-time kinetics of the uptake of $\mathrm{HOBr}$ and $\mathrm{BrONO}_{2}$ and in the presence of $\mathrm{HCl}$ in the temperature range 190-200 K, J. Geophys. Res., 102, 23 52923 541, 1997.

Ammann, M., Kalberer, K., Jost, D. T., Tobler, L., Rössler, E., Piguet, D., Gäggeler, H. W., and Baltensperger, U.: Heterogeneous production of nitrous acid on soot in polluted air masses, Nature, 395, 157-160, 1998.

Ammann, M.: Using ${ }^{13} \mathrm{~N}$ as tracer in heterogeneous atmospheric chemistry experiments, Radiochim. Acta, 89, 831-838, 2001.

Arens, F., Gutzwiller, L., Baltensperger, U., Gäggeler, H. W., and Ammann, M.: Heterogeneous reaction of $\mathrm{NO}_{2}$ on diesel soot particles, Environ. Sci. and Technol., 35, 2191-2199, 2001.

Barrie, L. A., Bottenheim, J. W., Schnell, R. C., Crutzen, P. J., and Rasmussen, R. A.: Ozone destruction and photochemical reactions at polar sunrise in the lower Arctic atmosphere, Nature, 334, 138-141, 1988.

Barrie, L. A., den Hartog, G., Bottenheim, J. W., and Landsberger, S.: Anthropogenic aerosols and gases in the lower troposphere at alert Canada in April 1986, J. Atmos. Chem., 9, 101-127, 1989.

Beichert, P. and Finlayson-Pitts, B. J.: Knudsen cell studies of the uptake of gaseous $\mathrm{HNO}_{3}$ and other oxides of nitrogen on solid $\mathrm{NaCl}$ : The role of surface-adsorbed water, J. Phys. Chem., 100, 15 218-15 228, 1996.

Blatchley, E. R., III, Johnson, R. W., Alleman, J. E., and McCoy, W. F.: Effective Henry's law constant for free chlorine and free bromine, Wat. Res., 26, 99-106, 1992.

Bottenheim, J. W., Gallant, A. G., and Brice, K. A.:, Measurements of $\mathrm{NO}_{\mathrm{Y}}$ species and $\mathrm{O}_{3}$ at 82 degrees $\mathrm{N}$ latitude, Geophys. Res. Lett., 13, 113-116, 1986.

Bottenheim, J. W., Barrie, L. A., Atlas, E., Heidt, L. E., Niki, H., Rasmussen, R. A., and Shepson, P. B.: Depletion of lower tropospheric ozone during Arctic spring: The Polar Sunrise Experiment 1988, J. Geophys. Res., 95, 18 555-18 568, 1990.

Cziczo, D. J. and Abbatt, J. P. D.: Infrared observations of the response of $\mathrm{NaCl}, \mathrm{MgCl}_{2}, \mathrm{NH}_{4} \mathrm{HSO}_{4}$, and $\mathrm{NH}_{4} \mathrm{NO}_{3}$ aerosols to changes in relative humidity from 298 to $238 \mathrm{~K}$, J. Phys. Chem. A, 104, 2038-2047, 2000.

Dancer, W.: Über die unterbromige Säure, Liebig's Ann. Chem., 125, 237-249, 1863.

Davies, J. A. and Cox, R. A.: Kinetics of the heterogeneous reaction of $\mathrm{HNO}_{3}$ with $\mathrm{NaCl}$ : Effect of water vapor, J. Phys. Chem. A, 102, 7631-7642, 1998.

Eichler, B.: Behaviour of volatile radionuclides in a tube with temperature gradient in vacuum, Zentralinstitut für Kernforschung, Rossendorf, 1977.

Eichler, B., Baltensperger, U., Ammann, M., Jost, D. J., Gäggeler, H. W., and Türler, A.: Thermochromatographic investigation on ${ }^{13} \mathrm{~N}$ labeled nitrous gases and of fission noble gases at low temperatures, Radiochim. Acta, 68, 41-49, 1995.

Eigen, M. and Kustin, K. J.: The kinetics of halogen hydrolysis, J. Am. Chem. Soc., 84, 1355-1361, 1962.

Fan, S.-M. and Jacob, D. J.: Surface ozone depletion in Arctic spring sustained by bromine reactions on aerosols, Nature, 359 , 522-524, 1992.

Fickert, S., Adams, J. W., and Crowley, J. N.: Activation of $\mathrm{Br}_{2}$ and $\mathrm{BrCl}$ via uptake of $\mathrm{HOBr}$ onto aqueous salt solutions, J. Geophys. Res., 104, 23 719-23 727, 1999.

Finlayson-Pitts, B. J., Livingston, F.vE., and Berko, H. N.: Ozone destruction and bromine photochemistry at ground level in the Arctic spring, Nature, 343, 622-625, 1990. 
Frenzel, A., Scheer, V., Sikorski, R., George, C., Behnke, W., and Zetzsch, C.: Heterogeneous interconversion reactions of $\mathrm{BrNO}_{2}$, $\mathrm{ClNO}_{2}, \mathrm{Br}_{2}$, and $\mathrm{Cl}_{2}$, J. Phys. Chem. A, 102, 1329-1337, 1998.

Fuchs, N. A. and Sutugin, A. G.: Highly dispersed aerosols. Ann Arbor Science Publishers, Inc., Ann Arbor, London, 1970.

Gäggeler, H. W., Eichler, B., Greulich, N., Trautmann, N., and Herrmann, G.: Vacuum-thermochromatography of carrier-free species, Radiochim. Acta, 40(3), 137-143, 1986.

Galbally, I. E., Bentley, S. T., and Meyer, C. P.: Mid-latitude marine boundary-layer ozone destruction at visible sunrise observed at Cape Grim, Tasmania, 41 degrees 5, Geophys. Res. Lett., 27, 3841-3844, 2000.

Galbally, I. E. and Roy, C. R.: Destruction of ozone at the Earth's surface, Q. J. R. Meteorol. Soc., 106, 599-620, 1980.

Gandrud, B. W. and Lazrus, A. L.: Preparation of tetrabutylammonium hydroxide for atmospheric sampling of acidic halogen gases, Anal. Chem., 55, 988-989, 1983.

Hanson, D. R., Ravishankara, A. R., and Solomon, S.: Heterogeneous reactions in sulfuric acid aerosols: a framework for model calculations, J. Geophys. Res., 99, 3615-3629, 1994.

Hanson, D. R.: Surface specific reactions on liquids, J. Phys. Chem. B, 101, 4998-5001, 1997.

Hausmann, M. and Platt, U.: Spectroscopic measurement of bromine oxide and ozone in the high Arctic during Polar Sunrise Experiment 1992, J. Geophys. Res., 99, 25 399-25 413, 1994.

Hebestreit, K., Stutz, J., Rosen, D., Matveiv, V., Peleg, M., Luria, M., Platt, U., Oltmans, S. J., and Komhyr, W. D.: DOAS measurements of tropospheric bromine oxide in mid-latitudes, Science, 283, 55-57, 1999.

Hirschfelder, J. O., Curtiss, C. F., and Bird, R. B.: Molecular theory of gases and liquids. John Wiley \& Sons, Inc., New York, London, Sydney, 1954.

Hu, J. H., Shi, Q., Davidovits, P., Worsnop, D. R., Zahniser, M. S., and Kolb, C. E.: Reactive uptake of $\mathrm{Cl}_{2}(\mathrm{~g})$ and $\mathrm{Br}_{2}(\mathrm{~g})$ by aqueous surfaces as a function of $\mathrm{Br}^{-}$and $\mathrm{I}^{-}$ion concentration: the effect of chemical reaction at the interface, J. Phys. Chem., 99, 8768-8776, 1995.

Kalberer, M., Tabor, K., Ammann, M., Parrat, Y., Weingartner, E., Piguet, D., Rössler, E., Jost, D. T., Türler, A., Gäggeler, H. W., and Baltensperger, U.: Heterogeneous chemical processing of ${ }^{13} \mathrm{NO}_{2}$ by monodisperse carbon aerosols at very low concentrations, J. Phys. Chem., 100, 15 487-15 493, 1996.

Kalberer, M., Ammann, M., Arens, F., Gäggeler, H. W., and Baltensperger, U.: Heterogeneous formation of nitrous acid (HONO) on soot aerosol particles, J. Geophys. Res., 104, 13 825-13 832, 1999.

Katrib, Y., Deiber, G., Schweitzer, F., Mirabel, P., and George, C.: Chemical transformation of bromine chloride at the air/water interface, J. Aerosol Sci., 32, 893-911, 2001.

Kirchner, U., Benter, T., Schindler, R. N., Hirokawa, J., Onaka, K., Kajii, Y., and Akimoto, H.: Experimental verification of gas phase bromine enrichment in reactions of $\mathrm{HOBr}$ with sea salt doped ice surfaces, Ber. Bunsenges. Phys. Chem., 101, 975-977, 1997.

Koga, Y., Takeo, H., Kondo, S., Sugie, M., Matsumura, C., McRae, G. A., and Cohen, E. A.: The rotational spectra, molecular structure, dipole moment, and hyperfine constants of $\mathrm{HOBr}$ and DOBr, J. Mol. Spectr., 138, 467-481, 1989.

Langendörfer, U., Lehrer, E., Wagenbach, D., and Platt, U.: Observation of filterable bromine variabilities during Arctic tropo- spheric ozone depletion events in high (1 hour) time resolution, J. Atmos. Chem., 34, 39-54, 1999.

Le Bras, G. and Platt, U.: A possible mechanism for combined chlorine and bromine catalyzed destruction of tropospheric ozone in the Arctic, Geophys. Res. Lett., 22, 599-602, 1995.

Lide, D. R.: CRC Handbook of Chemistry and Physics, CRC Press, Boca Raton, Ann Arbor, London, Tokyo, 1998.

Liu, Q. and Margerum, D. W.: Equilibrium and kinetics of bromine chloride hydrolysis, Environ. Sci. Technol., 35, 1127-1133, 2001.

Lock, M., Barnes, R. J., and Sinha, A.: Near-threshold photodissociation dynamics of $\mathrm{HOBr}$ : Determination of product state distribution, vector correlation, and heat of formation, J. Phys. Chem., 100, 7972-7980, 1996.

Long, F. and Olson, A.: The rate of exchange between chloride ion and chlorine in aqueous solution, J. Am. Chem. Soc., 58, 2214, 1936.

Luna, M., Rieutord, F., Melman, N. A., Dai, Q., and Salmeron, M.: Adsorption of water on alkali halide surfaces studied by scanning polarization force microscopy, J. Phys. Chem. A, 102, 6793-6800, 1998.

Malvestuto, V. and Ascoli, S.: A deliquescence model for alkali halide nuclei, Meteorol. Z., 10, 37-43, 2001.

McConnell, J. C., Henderson, G. S., Barrie, L., Bottenheim, J., Niki, H., Langford, C. H., and Templeton, E. M. J.: Photochemical bromine production implicated in Arctic boundary-layer ozone depletion, Nature, 355, 150-152, 1992.

Mickle, R. E.: Boundary layer ozone depletion during AGASP-II, Atmos. Environ., 23, 2443-2449, 1989.

Mochida, M., Akimoto, H., van den Bergh, H., and Rossi, M. J.: Heterogeneous kinetics of the uptake of $\mathrm{HOBr}$ on solid alkali metal halides at ambient temperature, J. Phys. Chem. A, 102, 4819-4828, 1998.

Mozurkewich, M.: Mechanisms for the release of halogens from sea-salt particles by free radical reactions, J. Geophys. Res., 100, 14 199-14 207, 1995.

Nagao, I., Matsumoto, K., and Tanaka, H.: Sunrise ozone destruction found in the sub-tropical marine boundary layer, Geophys. Res. Lett., 26, 3377-3380, 1999.

Noszticzius, Z., Noszticzius, E., and Schelly, Z. A.: On the use of ion-selective electrodes for monitoring oscillating reactions 1 . potential response of the silver halide membrane electrodes to hypohalous acids, J. Am. Chem. Soc., 104, 6194-6199, 1982.

Oltmans, S. J.: Surface ozone measurements in clean air, J. Geophys. Res., 86, 1174-1180, 1981.

Oltmans, S. J. and Komhyr, W. D.: Surface ozone distributions and variations from 1973-84 measurements at the NOAA Geophysical Monitoring for Climatic Change baseline observatories, J. Geophys. Res., 91, 5229-5236, 1986.

Orlando, J. J. and Burkholder, J. B.: Gas-Phase UV/Visible Absorption Spectra of $\mathrm{HOBr}$ and $\mathrm{Br}_{2} \mathrm{O}$, J. Phys. Chem., 99, 1143-1150, 1995.

Resnik, S. L., Favetto, G., Chirife, J., and Fontan, C. F.: A world survey of water activity of selected saturated salt solutions used as standards at $25^{\circ} \mathrm{C}$, J. Food Sci., 49, 510-513, 1984.

Ruasse, M.-F., Aubard, J., Galland, B., and Adenier, A.: Kinetic study of the fast halogen-trihalide ion equilibria in protic media by the Raman-laser temperature-jump technique. A nondiffusion-controlled ion-molecule reaction, J. Phys. Chem., 90, 4382-4388, 1986. 
Sander, R. and Crutzen, P. J.: Model study indicating halogen activation and ozone destruction in polluted air masses transported to the sea, J. Geophys. Res., 101, 9121-9138, 1996.

Schröter, W., Lautenschläger, K.-H., and Bibrack, H.: Taschenbuch der Chemie. Harry Deutsch, Thun, Frankfurt am Main, 1994.

Sedlacek, W. A., Lazrus, A. L., and Gandrud, B. W.: Measurements of stratospheric bromine, J. Geophys. Res., 89, 48214825, 1984.

Stutz, J., Hebestreit, K., Alicke, B., and Platt, U.: Chemistry of halogen oxides in the troposhere: Comparison of model calculations with fecent field data, J. Atmos. Chem., 34, 65-85, 1999.

Tang, T. and McConnell, J. C.: Autocatalytic release of bromine from Arctic snow pack during polar sunrise, Geophys. Res. Lett., 23, 2633-2636, 1996.

Taylor, R. S., Ray, D., and Garrett, B. C.: Understanding the mechanism for the mass accommodation of ethanol by a water droplet, J. Phys. Chem. B, 101, 5473-5476, 1997.

Tuckermann, M., Ackermann, R., Golz, C., Lorenzen-Schmidt, H., Senne, T., Stutz, J., Trost, B., Unold, W., and Platt, U.: DOAS-observation of halogen radical-catalysed Arctic boundary layer ozone destruction during the ARCTOC-campaigns 1995 and 1996 in Ny-Alesund, Spitsbergen, Tellus, 49B, 533-555, 1997.

Vogt, R., Crutzen, P. J., and Sander, R.: A mechanism for halogen release from sea-salt aerosol in the remote marine boundary layer, Nature, 383, 327-330, 1996.

Von Glasow, R., Sander, R., Bott, A., and Crutzen, P. J.: Modelling halogen chemistry in the marine boundary layer. 1 . Cloud-free MBL, J. Geophys. Res., submitted, 2001.

Wachsmuth, M., Eichler, B., Tobler, L., Jost, D. T., Gäggeler, H. W., and Ammann, M.: On-line gas-phase separation of short-lived bromine nuclides from precursor selenium, Radiochimica Acta, 88, 873-877, 2000.

Wachsmuth, M., Eichler, B., Tobler, L., Hänssler, F., Gäggeler, H. W., and Ammann, M.: Chemical characterisation of short-lived selenium and their daughter isotopes from thermal neutron induced fission of ${ }^{235} \mathrm{U}$ at a gas-jet facility, J. Radioanal. Nucl. Chem., in press, 2002.

Wahl, A. C. and Bonner, N. A.: Radioactivity applied to Chemistry, John Wiley \& Sons, Inc., New York, 1951.

Weingartner, E., Baltensperger, U., and Burtscher, H.: Growth and structural change of combustion aerosols at high relative humidity, Environ. Sci. Technol., 29, 2982-2986, 1995.

Wessel, S., Aoki, S., Winkler, P., Weller, R., Herber, A., Gernandt, H., and Schrems, O.: Tropospheric ozone depletion in polar regions - A comparison of observations in the Arctic and Antarctic, Tellus, 50B, 34-50, 1998.

Wilson, M. A. and Pohorille, A.: Adsorption and solvation of ethanol at the water liquid-vapor interface: A molecular dynamics study, J. Phys. Chem. B, 101, 3130-3135, 1997. 